\title{
Exposições: a prática social do design entre memórias e omissões
}

\author{
Exhibitions: the social practice of design between memories and omissions
}

ALBUQUERQUE, Fernanda Deminicis de; Mestranda; Pontifícia Universidade Católica do Rio de Janeiro (PUC-Rio)

fernanda.deminicis@gmail.com

CIPINIUK, Alberto; Doutor; Pontifícia Universidade Católica do Rio de Janeiro (PUC-Rio)

acipiniuk@gmail.com

\section{Resumo}

O presente texto é uma pequena reflexão acerca das possíveis contribuições e atribuições do designer em espaços museológicos, cujo objetivo é discutir, a partir de uma análise, as formas de inserção e atuação do design nestas instituições. Observando os estudos e usos que são feitos da cultura material em tais ambientes, o artigo também considera as relações entre diferentes partes que gravitam ao redor dos museus e a forma como se articulam a memória e as omissões que existem neste espaço. Trata-se também aqui da criação e de seus produtos e de como tais objetos se relacionam com a elaboração de narrativas museais, assumindo novas características e funções dependendo da forma pela qual são construídas e exibidas.

Palavras Chave: design; museus; exposição.

\begin{abstract}
The present text is a small investigation about the spaces and the attributions of the designers in museological spaces, proposing an analysis, as a way of presenting and thinking about the design inside this kind of institutions. Looking at the studies and uses of material culture in such environments, making considerations about the differences between the parts that gravitate around the museums, and how it articulates with memory and the information that exists in these spaces. The text also talks about the creation and its own products, and of the objects that are relate to the elaboration of museological narratives, assuming new characteristics and functions depending on how they are constructed and displayed.
\end{abstract}

Keywords: design; museums; exhibitions. 
Este breve artigo é baseado em um recorte de pesquisa em desenvolvimento de mestrado, no qual propomos abordar, a partir de uma análise, as possibilidades de atuação e de emprego do design nos museus, em que, de forma sucinta, o problema identificado são as relações existentes entre estes, as instituições mantenedoras do patrimônio histórico brasileiro, suas obras, seus objetos e suas exposições, o espaço que ocupam e seus visitantes. Tais como todas as relações humanas, estas acima enunciadas são complexas e multifacetadas, devendo ser observadas e estudadas dentro de seu contexto histórico, social, político e econômico. Nesta conjuntura, procuramos identificar a contribuição que o Campo do Design ${ }^{1}$ pode oferecer ao espaço museológico e aos estudos e às disposições que são feitos da cultura material em tais ambientes. Museus são reflexos expressivos do que uma sociedade construiu e a que atribuiu valor.

Por princípio convencionado e apontado como característica elementar pelo International Council of Museums (ICOM), os museus possuem importante função (que deve resultar na prática) social contemporânea, que se expressa principalmente no seu papel de educar. Ora, sua atribuição é suscitar reflexão e aprendizado de modo que apareça aos seus visitantes como uma espécie de entretenimento, enquanto atuam categoricamente na formação de valores simbólicos e arbitrários culturais, que se apresentam de forma lúdica, em que recursos materiais se emulam com narrativas, que muitas vezes passam despercebidas ao distraído visitante.

Do mesmo jeito, o design tem seu papel social enquanto prática, entendida aqui como uma praxis, uma "forma de trabalho [que] visa um resultado concreto com algum valor social, isto é, uma forma de trabalho que seja essencialmente útil".2

Ora, se inicialmente o objeto industrial poderia ser chamado de utilitário ${ }^{3}$, conforme a sociedade foi se modificando e criando novas demandas, esses objetos transformaram-se em mercadorias, passando a ter uma dimensão simbólica que cada vez foi se tornando mais expressiva, de modo que hoje muitas vezes ela suplanta as suas características práticas, ou o eventual valor de uso que os objetos industriais poderiam ter tido algum dia. Com todas essas possibilidades, a indústria, de certa maneira, encontrou uma forma de se beneficiar modus operandi da prática do design em sua corrida para aumento de vendas, em um processo que visa criar valores evanescentes ou simbólicos, mudando a estética superficial da aparência dos produtos, que no interior não apresentam nenhuma inovação técnica, a fim de criar desejo pela compra de algo que não seria novo, no sentido de oferecer uma nova utilidade ou valor de uso para as pessoas, mas apenas uma novidade em termos estéticos e formais. Isso foi, e ainda é, amplamente comum no design, sendo que na década de 1950, ficou amplamente conhecido como styling, cuja origem remonta à indústria automobilística, ainda nos anos 30 do século XX, quando surgiu como resultante da ação de uma dupla pressão: a demanda por preços cada vez mais baixos, o que se resolvia até então a partir de uma mera padronização dos produtos, e o carecimento de novidades para reter o interesse dos consumidores. ${ }^{4}$

\footnotetext{
${ }^{1}$ Aqui, a noção de Campo foi tomada de Pierre Bourdieu, cf. BOURDIEU, Pierre. A economia das trocas simbólicas. São Paulo: Perspectiva, 2015, passim.

${ }^{2}$ CIPINIUK, Alberto. O Campo do Design e a crise do monopólio da crença. São Paulo: Editora Blücher, 2017 , p. 49.

${ }^{3}$ Distinguimos aqui o que é o valor de uso e o valor de troca dos objetos na sociedade industrial. Dessa forma, o valor de uso é quando o objeto é utilitário ou funcional; já o valor de troca simbólica é quanto ele se presta a produzir distinção social, que, no nosso caso, é a sua frivolidade, tal como encontramos nos objetos de luxo.

${ }^{4}$ HESKETT, John. Desenho Industrial. Rio de Janeiro: Editora José Olympio, 2006, p. 74.
} 
Ocorre que, com a grande quantidade de oferta de produtos similares disponíveis no mercado, qualquer objeto se torna apenas mais um entre tantos, o que faz com que não agregue valores sociais, servindo apenas para expandir a produção e o consumo de objetos desnecessários, criando uma economia de trocas simbólicas. ${ }^{5}$ Assim, muitas vezes o ato da compra, da necessidade de aquisição, é impulsionado pelo simples desejo criado pela sensação de status que aquela posse pode acarretar. O desejo, não se pode enganar, é proveniente da própria associação do design com as indústrias e os mercados, e por estes também é saciado, satisfeito, quando os mercados disponibilizam seus frutos para aquisição. Convém aqui se tratar de assunto já enunciado por Baudrillard, que observa com propriedade que, tal como diversas classes sociais, os objetos também possuem classes distintas para atender a estas estratificações da sociedade. Ainda assim, as hierarquias entre os objetos, diferentemente do que acontece com os homens, são atenuadas pela sua serventia, pelo seu manuseio, pois, luxuosos ou simples, dedicam-se a uma mesma função primária de uso. ${ }^{6}$ Certamente essa hierarquia também se dá no âmbito expositivo, pois não seria improvável se encontrar dois mesmos objetos em um espaço comum, onde um se mostra em uso ordinário e outro patrimonializado como acervo por alguma determinada razão.

É conveniente se esmiuçar a relação entre o design e o status. Efetivo criador de distinção social, o design elabora noções de pertencimento e é capaz de originar uma série de objetos e códigos que facilitam o reconhecimento entre os pares. Quando outros que não pertencem àquele dado grupo são capazes de não só interpretar os códigos, mas também de incorporá-los em seus repertórios, o sistema é pressionado a inovar. Parece ser natural para os seres humanos se mostrarem receosos às mudanças bruscas, pois estas geram insegurança e, portanto, resistência. Podemos aqui lembrar os estudos sobre a cultura popular e os costumes de Thompson, em que figuram questões que nos são pertinentes até o presente momento. Assim, ele destaca que:

A inovação é mais evidente na camada superior da sociedade, mas ela não é um processo tecnológico/social neutro e sem normas (...), mas sim a inovação do processo capitalista, quase sempre experimentada pela plebe como uma exploração, a expropriação de direitos de uso costumeiros $(. . .)^{7}$

Já que esta camada superior precisa sempre buscar distância daquilo que se classifica como popular, ocorre que, quando o sistema permitir que classes menos abastadas tenham acesso aos produtos e códigos que conferem status social, o popular estabelece um movimento que busca preservar essa frágil isonomia, que perdurará até que o próprio sistema decida que é momento de reiniciar o seu ciclo, criando novamente as antigas distâncias de classes. Portanto, reiteramos aqui o paradoxo apontado por Thompson, que aponta que a cultura popular é tradicional, pois resiste à inovação, mas também é rebelde, justamente por pretender conservar tal tradição, ou até mesmo uma determinada posição social já conquistada.

Nesse panorama, por entregar valores que são frágeis e rapidamente descartáveis e substituíveis, justo por sua volatilidade sujeita a modismos estéticos, o valor social do design segue abalado, custando muitas vezes a sua credibilidade perante outros campos do saber, fazendo com que seja associado apenas a uma produção de materialidade, ocasionando um esquecimento de sua possível contribuição teórica e até levando a um desprezo por áreas acadêmicas mais tradicionais.

\footnotetext{
${ }^{5}$ Termos utilizados por Pierre Bourdieu, cf. op. cit.

${ }^{6}$ BAUDRILLARD, Jean. O sistema dos objetos. São Paulo: Editora Perspectiva, 2015, p. 146.

${ }^{7}$ THOMPSON, E. P. Costumes em comum: estudos sobre a cultura popular tradicional. São Paulo: Editora Cia. das Letras, 1998, p.19.
} 
Antes de prosseguir no texto, é preciso elucidar com mais clareza o que aqui foi supracitado como o Campo do Design, que deve ser entendido como uma unidade de produção de saber e de bens materiais, voltado para a sociedade e incorporado a ela e em suas múltiplas relações peculiares. Inserido em contexto de viés social, tal Campo procuraria uma compreensão de seus produtos ou objetos como elementos pertencentes à cultura, e que, dessa forma, configuram-se em noções que são arbitrárias, condicionadas e elaboradas por grupos que estabelecem um habitus que se fortalece e se perpetua em proporção à imbricação das partes que o compõem e que dele comungam. $^{8}$

Convém ressaltar que Pierre Bourdieu nunca tratou do Design, mas sim da Arte, conceituando como Campo a relação entre três partes que se avigoram em suas relações, constituindo a produção, o que, nessa transposição de conceitos, podemos entender como os designers e outros profissionais que gravitam no entorno da criação, do desenvolvimento e da produção; a recepção, que consideraremos aqui, de forma simplificada, o grupo dos usuários e consumidores de tudo aquilo que é entregue pelos produtores; e a circulação, que se trata dos agentes que legitimam e difundem de acordo com inúmeros interesses existentes, sejam eles de cunho ideológico, político ou mercadológico, e que atuam como uma espécie de intermediários de alta eficácia e eficiência entre os que produzem e os que recebem. ${ }^{9}$

Tais associações também são válidas para se observar o desenrolar das relações que se passam no interior de museus, cujo veículo principal são as exposições. De um lado, criadores e diferentes tipos de profissionais envolvidos na elaboração e produção de uma exposição; de outro, os visitantes, sejam esses leigos ou doutos. Todos estes personagens se encontram no interior das salas de exibição, submetidos ao ideal e à legitimação de uma instituição que circula e que veicula aquelas obras e os objetos e textos apresentados e que permite que ambas as partes (produtores e visitantes) efetuem em seu interior as suas trocas. Assim posto, um olhar mais acurado sobre estes mencionados espaços de troca se faz necessário.

Exposições, termo que se deriva do latim exponere, tem em sua origem a noção de pôr para fora, entregar à sorte. Como hoje a entendemos, uma exposição deve trazer em seu cerne os sentidos que os seus organizadores desejam fazer chegar ao público, sendo, portanto, um veículo que leva os objetos, sejam estes de arte ou prosaicos, até os visitantes. É justamente nessa exposição que uma dada instituição encontra uma forma de se comunicar, criando inclusive uma identidade própria para esses discursos, entendidos aqui como a organização intencional de ideias que se apresentam de maneira a instilar determinado raciocínio e sentimentos a quem a ele é submetido e que, quando se solidificam, tornam-se fortes e dignificam a autoridade de quem fala a outrem. Retomando o conceito original do exponere, o deixar à sorte, nos domínios da Fortuna ${ }^{10}$, significa a priori que não é possível se deter as rédeas das conexões, associações e apropriações que os visitantes irão efetuar, propagando aquilo que lhes está sendo apresentado. Dessa maneira, de que artifícios as instituições podem valer-se para reger o conteúdo das suas exposições? Uma delas, certamente, é o uso consciente do design.

Por meio da inserção do design nos museus, é possível criar ambientes que arranjem e que combinem de forma proposital todos os elementos e recursos de que se pode lançar mão para que

\footnotetext{
${ }^{8}$ CIPINIUK. Op. cit., p. 134.

9 BOURDIEU. Op. cit.

${ }^{10}$ A Fortuna, aqui tratada, está referida como a deusa da mitologia que geria o acaso, o destino, a boa e a má sorte. Fortuna é capaz de manifestar seus propósitos de forma aleatória, cujas circunstâncias não podem ser previstas, determinadas e nem controladas.
} 
as exposições, apresentadas em circuitos ou não, sejam capazes de domesticar e conduzir os visitantes pelo caminho que se deseja, restando pouco espaço para operar o temido acaso. Assim posto, podemos ainda levar em consideração que, com o auxílio do design, o ato de expor objetos, compreendidos como bens culturais legitimados por instituições competentes, incrementa a forma de afirmá-los como essenciais para uma determinada história e, portanto, uma memória.

Ao tratar de museus, em especial os de caráter histórico, é relevante se destacar o papel da memória e da história. Em seu trabalho, quando se debruça sobre a memória, Le Goff traz uma referência ao pensamento de São Tomás de Aquino, que, baseado em uma materialidade que se fundamentava em Aristóteles, acreditava que, para reter de forma adequada a memória, algo tão intangível e fugaz, esta deveria estar associada a qualquer coisa sensível que pudesse ser símbolo para ela. Ora, a partir do momento que se liga tal memória aos objetos, passa a existir um conjunto de coisas materiais que têm valor simbólico para uma coletividade, que será uma das grandes responsáveis pela criação e valorização de um patrimônio cultural. Esses guardados ou arbitrários culturais são capazes de manter e fortalecer a união daquelas pessoas que os partilham e que, assim, os expandem cotidianamente ao logo dos tempos. ${ }^{11}$ No que se alude aos resquícios materiais do passado que chegam até nosso presente, cito que estes "são [...] produtos de uma operação seletiva que traduz o controle sobre as informações que a sociedade exerce sobre si mesma". ${ }^{12}$

Elementarmente, então, trazendo tal argumento para os museus, e retomando o que já foi afirmado, podemos pensá-los como resultados concretos do que uma sociedade elaborou e edificou e a que atribuiu valor. Mais especificamente, ter controle e gerência sobre dado patrimônio cultural histórico faz também com que as instituições tenham domínio não só da memória que lhes cabe, como também dos silêncios que lhes são pertinentes, sendo interessante observar que o conteúdo selecionado a ser exibido, bem como o discurso que sua proposta museal irá formar, é capaz de retratá-la, ainda que de forma tácita, não sendo clara ou direta.

Assim, circuitos expositivos trazem artifícios planejados, combinando objetos, imagens, cheiros, sons e textos, repletos de representação de valor simbólico, que unem conteúdo expressivo de informação com estímulos sensoriais que se propõem a fazer sentido ao visitante, versando sobre determinados racontos e omitindo tantos mais, de forma a atingir objetivos e suprir demandas das instituições que os criam e sustentam, sendo fulcral que sejam apreciados de forma atenta e crítica. Enunciam, portanto, uma memória que é dita oficial e que se edifica a partir de um movimento que reprime outros tipos de manifestações de cunho tão político quanto ela própria. ${ }^{13}$ Dessa maneira, muitas vezes há uma tensão criada nesses espaços expositivos, resultante justo da disputa entre as diferentes ideologias ali estão presentes, onde talvez apenas uma será explícita, mas que de forma alguma anula aquelas que foram forçosamente silenciadas.

Ao refletirmos melhor sobre os objetos, podemos perceber que eles são capazes de se disfarçar, escondendo em si muitas especificidades que não podemos ver se os observarmos de forma simplória. Eles camuflam suas intenções de criação, seus métodos produtivos, o modo de trabalho pelo qual se originaram, o emprego de seu uso, as formas pelas quais se ressignificaram em diferentes espaços, e o seu real valor sem suas máscaras simbólicas. Imprescindível salientar que os objetos situam-se em tempos históricos específicos, o que atribui a eles valor de uso, de

\footnotetext{
11 LE GOFF, Jacques. História e Memória, Livro II: Memória. Lisboa: Editora Edições 70, 2000.

12 KNAUSS, Paulo. 0 desafio de fazer História com imagens: arte e cultura visual. ArtCultura, Uberlândia, v. 8, n. 12, p. 97-115, jan.-jun. 2006, p. 5.

13 RAMOS, Francisco Regis Lopes. A danação do objeto. Chapecó: Editora Argos, 2004, p.46.
} 
troca simbólica e de distinção social. Em uma relação dialética, podemos observar que o homem cria os objetos para um determinado uso, o que, por sua vez, molda hábitos e condiciona o usuário a partir da forma de fazer e operar que o objeto impõe.

O mesmo ocorre com os objetos que se encontram em instituições de guarda patrimonial. De qualquer natureza, os museus "arrancam" objetos de sua própria temporalidade e contextos originais, conferindo-lhes novos sentidos e novas serventias e conveniências, ao passo que entregam novas razões simbólicas aos mesmos. Aqui, o design presta-se como ferramenta expressiva para essa atribuição de novos significados, abrindo um enorme leque de possibilidades de sentidos. $E$, como os objetos, também os visitantes e espectadores de exibições são sujeitos constituídos por seus tempos e culturas, de forma que suas percepções (intelectuais e sensíveis) são condicionadas por seus meios sociais e culturais.

Observando então a forma como se monta uma exposição e seu respectivo discurso, não se pode deixar de lado que, por trás de toda sua criação, há pessoas que conscientemente trabalham tecendo narrativas, sugerindo recortes e argumentos, dispondo de objetos calculadamente selecionados e arrumados de forma deliberada, quase autocráticas. Nada, por certo, é exibido sem um pensamento prévio ou objetivo traçado que se almeja alcançar - da iluminação às cores, às vitrines, aos textos, ao percurso bem demarcado, ou até mesmo um caminho que se mostre livre ao visitante. Desde que os museus passaram de dépôts para se tornarem expôts ${ }^{14}$ (e aqui, em uma origem na tradição do antiquariado, fazemos uma referência à passagem dos gabinetes de curiosidade para os museus nos moldes como hoje os conhecemos), não há como se pensar suas exibições sem considerar as intenções e o manejo dos objetos que o museu possui em sua guarda.

Assim, é imprescindível se compreender que os objetos e produtos variados da cultura material, sejam eles triviais ou de arte, tridimensionais ou não, não emitem por si só os seus significados e nem são passíveis de serem "lidos" como uma espécie de texto com acepção constante e imanente. Sendo a sociedade uma coletividade, produtora de significados e de crenças, entende-se que esta inculca e molda coercitivamente um habitus, ou seja, a forma como cada indivíduo percebe o seu entorno, de acordo com inúmeros interesses coletivos - os determinismos sociais -, que geralmente são ocultos. Dessa forma, não poderiam os objetos criados pela sociedade emitir sentidos, e sim nós, enquanto pertencentes a essa cultura e partícipes dela, partilhando dos mesmos códigos e do mesmo tempo histórico, projetamos esses sentidos, significados e simbolismos dos objetos. Isso é muito claro no pensamento de Didi-Huberman ${ }^{15}$ quando ele diz que não "percebemos" as coisas do mundo, mas sim as "reconhecemos". Ora, podemos então inferir que o olhar precisa ser condicionado e treinado para ver aquilo que se deseja mostrar. Não há um olhar neutro ou gratuito, sem um porquê.

Aqui se chega ao momento de lidar com assunto que é dito caro aos designers: o público. Neste texto, por ocasião de nos debruçarmos sobre instituições museais, o trataremos genericamente por visitantes (conforme já os denominamos até aqui). No intuito de garantir que a narrativa e a mensagem passadas pela instituição por meio da exposição cheguem com o mínimo de ruídos e imprecisões, o museu deve analisar com profundidade as motivações e os anseios dos visitantes, construindo uma sapiência sobre o comportamento dos mesmos e proporcionando reflexões por meio de diferentes propostas culturais que possam enriquecer não só o

\footnotetext{
14 Termos utilizados por Dominique Poulot, cf. POULOT, Dominique. Museu e museologia. Belo Horizonte: Editora Autêntica, 2013, p. 27.

15 DIDI-HUBERMAN, Georges. 0 que vemos, o que nos olha. São Paulo: Editora 34, 2010, passim.
} 
conhecimento, mas, por consequência a experiência estética etc. Para se lograr sucesso em empreitada tão ambicionada, é primordial que, conhecendo o visitante, não se extrapole os seus limites de absorção de informação, conforme ressalta Bourdieu no trecho abaixo:

\begin{abstract}
a riqueza da "recepção" [depende], antes de tudo, da competência do "receptor", ou seja, do grau de seu controle relativamente ao código da "mensagem". Cada indivíduo possui uma capacidade definida e limitada de apreensão da "informação" proposta pela obra, capacidade que depende de seu conhecimento global (...) quando a mensagem excede as possibilidades de apreensão do espectador, este não apreende sua "intenção" e desinteressa-se do que the parece ser uma confusão sem o menor sentido, ou um jogo de manchas de cores sem qualquer utilidade ${ }^{16}$
\end{abstract}

Enunciadas essas questões, outro aspecto interessante de se abordar é que o design pode e é usado por interesses políticos para criar e consagrar a noção de pertencimento, e ser artifício que, no caso dos museus, pode facilitar este reconhecimento desejado, criando um ambiente que seja mais confortável e aprazível ao visitante. Nesse ponto, não se pode deixar de mencionar a referência de Forty, que destaca com propriedade que o design nunca é empregado de forma ingênua, exemplificando, ainda que de forma anacrônica, que "impérios, exércitos, marinhas, ordens religiosas e empresas modernas, todos usaram design para transmitir ideias sobre o que são [e o que projetam], tanto para o público interno como para o mundo exterior" ${ }^{17}$

Em contraponto, o design pode também, dependendo da proposta, moldar recinto de provocação e incômodo, em uma tentativa de impelir um movimento ou posicionamento crítico no visitante. Há ainda aqui uma ressalva: o designer pode sim reproduzir noções, mas é importante se observar que nem sempre é eficaz em suas intenções, ressaltando-se que a concepção de que o designer resolve problemas é um postulado mítico desta categoria.

O design, assim como os museus, cria crenças. Como produtos da própria sociedade, eles pouco a pouco, com engenho, vão estabelecendo e produzindo tradições e objetos de culto, até estes se tornarem axiomas. ${ }^{18}$ Transmutam-se em fundamentos inquestionáveis, como uma crença que se sobrepõe a todas as outras, sendo assim reproduzida maquinalmente sem mais questionamentos. Curioso inclusive apontar que, em alguns casos, objetos próprios de design, após perderem sua função, ou seja, quando considerados obsoletos, tornam-se acervo em museus, o que nos permite concluir que "o que tinha valor de uso torna-se espetáculo". ${ }^{19} \mathrm{~A}$ beleza que muitas vezes é vista em objetos antigos, dispostos nos museus, provém meramente da sua sobrevivência ao tempo, da sua tenacidade de não se decompor. Despertam a curiosidade e fascinam por terem presenciado épocas que nós não podemos testemunhar. Como nos diz Ramos, o museu é:

lugar onde o tempo é visto, não como reflexo, representação ou resgate do passado, mas como experiência de múltiplas sensações e reflexões que se constituem a partir dos objetos e sobretudo a partir do modo pelo qual os objetos estão dispostos. Ver o tempo não significa ver o passado, mas visualizar na materialidade do que é exibido no tempo (...) Ver as inúmeras passagens do tempo no objeto, passar pelo objeto, imaginando, sentindo o que

\footnotetext{
${ }^{16}$ BOURDIEU, Pierre; DARBEL, Alain. O amor pela arte: os museus de arte na Europa e seu público. Porto Alegre: Editora Zouk. 3 edição. 2016, p.69.

${ }^{17}$ FORTY, Adrian. Objetos de desejo - design e sociedade desde 1750. São Paulo, Editora Cosac \& Naify, 2013, p. 301.

18 HOBSBAWN, Eric; RANGER, Terence. A invenção das tradições. Rio de Janeiro, São Paulo: Editora Paz e Terra, 2015. passim.

${ }^{19}$ RAMOS. Op. cit., p.64.
} 
o objeto pode ter sido e por que foi parar no museu, reformulando a separação entre ficção e realidade. ${ }^{20}$

No museu, o design se potencializa em sua capacidade de criar valor simbólico, apropriandose de artefatos que já são convencionados como acervo e, portanto, já merecedores de apreço diferenciado, e os elevando à condição de sagrados, colocando-os sob um foco de luz especial, em vitrines que não permitem seu contato direto, em pedestais altos e imponentes, no centro de amplos espaços, como protagonistas únicos de um verdadeiro espetáculo, pois a "cenografia (...) não é somente a tradução de pesquisas, mas uma área específica que possibilita (ou não) a vitalidade do objeto exposto". ${ }^{21}$

Para que os próprios profissionais atuantes inseridos em instituições museais, e aqui destacamos os designers, não se permitam ludibriar, é primordial que entendam com responsabilidade sua praxis, sua prática de trabalho despida de fantasias, em que ela deixa de ser compreendida como um processo, capaz de tudo resolver com fórmulas enunciadas e engessadas, assentada no credo de que este se desenvolve com a criatividade singular do designer. ${ }^{22}$

É imprescindível que o design se coloque como ferramenta poderosa para contribuir com a reflexão não só do passado, por meio dos objetos que chegam ao nosso presente, mas também da própria consciência histórica dos visitantes. E que o design colabore com seu Campo de maneira a criar exposições que possam estimular o juízo crítico dos seus observadores e que, por consequência, some a sua própria função social à função social dos museus.

Atribuindo-se tão criativos como artistas, os designers conferem caráter quase que transcendental à sua metodologia projetual, equiparando-a à noção idealizada da criação da arte. Grande parte do que é aceito em comum acordo entre os pares não é calcado na teoria, mas na empiria das ações práticas, confundindo suas observações do dia a dia com formulações teóricas e de caráter científico. Tais profissionais manipulam objetos da cultura material, revisitando concepções já existentes, recombinando-as e dando novos rumos a elas, misturando épocas, culturas, curiosidades, estéticas, hábitos etc. ${ }^{23}$

Retomando o contexto dos museus, podemos deliberar um pouco mais sobre as competências de planejamento e projeto de uma exposição ao observarmos a própria noção do que se convencionou ser a criação. Tratados em geral à guisa rasa e hegemônica, os criadores (que aqui consideraremos como designers e artistas) são dotados de liberdade e autonomia, como um tipo possuidor de gênio (ingenium) que lhe proporciona permissividade para ceder a seus impulsos e paixão inatas. Tal conceito surge na Modernidade dos séculos, e mais uma vez pode e deve ser estudado por meio da materialidade que resulta das transformações ocorridas de valor, significado e uso nas obras dos artistas, quando estes deixam de ser meros artífices ou artesãos, e nas dos designers, quando seus produtos se tornam capazes de fomentar e alimentar desejos de consumo. Materialidade esta que hoje, em nossa contemporaneidade, pode ser encontrada em salas de exposições por todo o mundo.

Com todo o supracitado, chegamos enfim ao nosso objetivo, que é discutir, a partir de uma análise, as formas de inserção e atuação do design nos museus, muito além da óbvia e epidérmica

\footnotetext{
${ }^{20}$ Ibidem, p.151.

21 Ibidem, p.150.

22 CIPINIUK. Op. cit., p.44-45.

23 DEMINICIS, Fernanda; CIPINIUK, Alberto. Os usos da criação: considerações sobre a criação artística e sua apropriação pelo Campo do Design. Revista Tamanduá, Rio de Janeiro, n.4-v.1, ano 4, p.1-10, 2017, passim.
} 
conhecida elaboração de material de divulgação, identidades visuais e outros materiais secundários de apoio às exposições, reforçando a importância do estudo minucioso da cultura material e da sociedade que gravita em seu entorno.

As imagens e os objetos são poderosas fontes de pesquisa ainda pouco exploradas, sendo na maior parte das vezes aplicadas como meras ilustrações e exemplos em estudos acadêmicos. Há que se apropriar desses recursos como documentos, explorando de que maneiras eles são capazes de contribuir para o alargamento das pesquisas e do saber, sendo aliados dos pesquisadores, e não meros coadjuvantes. Para que se logre sucesso em tal empreitada, é de suma importância se ter rigor a uma metodologia de trabalho que conduza o uso dessas imagens e desses objetos, sem olvidar que estes não possuem significados per si e, portanto. não irão sozinhos "contar" verdades ou "revelar" segredos inerentes à sua materialidade ou forma. Apesar de tais métodos de condução de pesquisa e investigação extrapolarem em muito o conteúdo deste artigo, não podem deixar de aqui estar registrados para reforçar e reiterar sua importância para os pesquisadores.

Deve-se ressaltar também a relevância dos museus, que, enquanto instituições de posse de uma larga gama de bens patrimoniais, devem investir nessas pesquisas, fomentá-las e conduzi-las , sendo de extrema importância que busquem validar o uso das imagens e dos objetos como fonte histórica ${ }^{24}$, demonstrando na prática a riqueza que podem oferecer a diversas áreas do saber (inclusive o próprio design), justo porque traduzem a infindável capacidade e diversidade das sociedades, com suas complexas estruturas, em produzir e significar material sensível.

\section{Referências}

BAUDRILLARD, Jean. O sistema dos objetos. São Paulo: Editora Perspectiva, 2015.

BOURDIEU, Pierre. A economia das trocas simbólicas. São Paulo: Editora Perspectiva, 2015.

BOURDIEU, Pierre. A produção da crença: Contribuição para uma economia de bens simbólicos. Porto Alegre: Editora Zouk. 2006.

BOURDIEU, Pierre; DARBEL, Alain. O amor pela arte: os museus de arte na Europa e seu público. Porto Alegre: Editora Zouk. 3a edição. 2016.

CIPINIUK, Alberto. O Campo do Design e a crise do monopólio da crença. São Paulo: Editora Blücher, 2017.

DEMINICIS, Fernanda; CIPINIUK, Alberto. Os usos da criação: considerações sobre a criação artística e sua apropriação pelo Campo do Design. Revista Tamanduá, Rio de Janeiro, n.4-v.1, ano 4, p.1-10, 2017.

DIDI-HUBERMAN, Georges. Diante da imagem. São Paulo: Editora 34, 2013.

DIDI-HUBERMAN, Georges. O que vemos, o que nos olha. São Paulo: Editora 34, 2010.

HESKETT, John. Desenho Industrial. Rio de Janeiro: Editora José Olympio, 2006.

HOBSBAWN, Eric; RANGER, Terence. A invenção das tradições. Rio de Janeiro, São Paulo: Editora Paz e Terra, 2015.

24 DIDI-HUBERMAN, Georges. Diante da imagem. São Paulo: Editora 34, 2013, passim. 


\section{Artigo Completo}

KNAUSS, Paulo. O desafio de fazer História com imagens: arte e cultura visual. ArtCultura, Uberlândia, v. 8, n. 12, p. 97-115, jan.-jun. 2006.

LE GOFF, Jacques. História e Memória, Livro II: Memória. Lisboa: Editora Edições 70, 2000.

POULOT, Dominique. Museu e museologia. Belo Horizonte: Editora Autêntica, 2013.

RAMOS, Francisco Regis Lopes. A danação do objeto. Chapecó: Editora Argos, 2004.

THOMPSON, E. P. Costumes em comum: estudos sobre a cultura popular tradicional. São Paulo:

Editora Cia. das Letras, 1998. 